\title{
Patient and referring health care provider satisfaction with a physiotherapy spinal triage assessment service
}

This article was published in the following Dove Press journal:

Journal of Multidisciplinary Healthcare

22 December 201I

Number of times this article has been viewed

Brenna Bath'

Bonnie Janzen²

'School of Physical Therapy, College of Medicine, University of Saskatchewan,

${ }^{2}$ Community Health and Epidemiology, College of Medicine, University

of Saskatchewan, Saskatoon,

Saskatchewan, Canada
Correspondence: Brenna Bath

I I I College Drive, Saskatoon SK,

Canada S7N OW3

Tel +l 3069666573

Fax +l 3069666575

Email brenna.bath@usask.ca
Purpose: To evaluate participant and referring care provider satisfaction associated with a spinal triage assessment service delivered by physiotherapists in collaboration with orthopedic surgeons.

Methods: People with low back-related complaints were recruited from those referred to a spinal triage assessment program delivered by physiotherapists. Measures of patient and provider satisfaction were completed at approximately 4 weeks after the assessment. The satisfaction surveys were analyzed quantitatively with descriptive statistics and qualitatively with an inductive thematic approach of open and axial coding.

Results: A total of 108/115 participants completed the posttest satisfaction survey. Sixty-six percent of participants were "very satisfied" with the service and 55\% were "very satisfied" with the recommendations that were made. Only $18 \%$ of referring care providers completed the satisfaction survey and $90.5 \%$ of those were "very satisfied" with the recommendations. Sixtyone participants and 14 care providers provided comments which revealed a diverse range of themes which were coded into positive (ie, understanding the problem, communication, customer service, efficiency, and management direction), negative (ie, lack of detail, time to follow-up, cost) and neutral related to the triage service, and an "other" category unrelated to the service (ie, chronic symptoms, comorbidities, and limited access to health care.)

Conclusion: The quantitative results of the participant survey demonstrated very high levels of satisfaction with the service and slightly less satisfaction with the recommendations that were made. Satisfaction of referring care providers with the recommendations and report was also high, but given the low response rate, these results should be interpreted with caution. Qualitative analysis of participant and provider comments revealed a diverse range of themes. These other issues may be important contextual factors that have the potential to impact patient relevant outcomes.

Keywords: interprofessional practice, quality assurance, back pain, orthopedics

\section{Introduction}

Accessibility to health care services and satisfaction are key components of quality of care. Wait time has been identified by Canadians as an important measure of access and is cited as the most prominent barrier among those who experience difficulties obtaining care. ", "Satisfaction" can refer to a health care recipient's reaction to aspects of the service delivered which, in turn, affects overall perceptions of quality of service. ${ }^{3}$

Long wait times for elective orthopedic surgery have been and continue to be problematic in Canada. ${ }^{4}$ People waiting for health care can experience adverse effects such as reduced function, lower health-related quality of life, and psychological distress; ${ }^{1,5-7}$ and living with uncertainty of diagnosis, prognosis, and further management may create 
or perpetuate patient concerns. ${ }^{8}$ People with spine-related complaints comprise a large proportion of referrals made to orthopedic surgeons. ${ }^{9,10}$ Many of these patients are not considered to be surgical candidates ${ }^{11,12}$ and may simply require reassurance that they do not have serious spinal pathology. ${ }^{13,14}$ This patient subgroup can contribute significantly to wait times for consulting with a surgeon which ultimately leads to greater wait times for other required orthopedic surgical procedures such as hip and knee joint replacements. Reducing the number of nonsurgical consultations in a surgeon's caseload may help reduce surgical consultation wait times for patients who may benefit from spinal surgery and may potentially redirect nonsurgical candidates to more appropriate treatment earlier. There is, therefore, a need for innovative approaches to the management and reduction of orthopedic wait times.

Physiotherapists (PTs) are primary health care providers who have expertise in the assessment and evaluation of musculoskeletal disorders. Interprofessional models of care that include PTs as key providers are an alternative approach to traditional physician-centered referral and care pathways. There is a growing body of evidence to support new and expanded roles that maximize the unique skill sets of PTs. PTs with advanced orthopedic training, often practicing with a maximized or extended scope, have been shown to be equally as effective as orthopedic surgeons for the diagnosis and nonsurgical management of many musculoskeletal conditions. ${ }^{15-20}$ PTs performing this role have also contributed to reduced wait times and improved referral practices, ${ }^{19,21}$ with data from the United Kingdom indicating that pre-screening of patients by such therapists can more than double the proportion of patients who need surgery on assessment by the surgeon. ${ }^{22}$ This type of role can be referred to as triage, ${ }^{23}$ whereby patients are first screened by a PT to determine whether referral to a surgeon, recommendation of further conservative management, and/or diagnostic investigations is appropriate.

Much of the research evaluating such programs has focused on general orthopedic practices ${ }^{19,24-26}$ or hip and knee arthritis management only. ${ }^{27-29}$ Few PT-delivered triage services focused solely on spinal conditions are described or evaluated in the literature. ${ }^{21,30,31}$

A spinal triage program delivered by PTs represents a shift in roles that may affect patient and referring care provider expectations, given that both groups may be accustomed to interacting with orthopedic surgeons for management of complex and/or chronic back problems that have been recalcitrant to conservative care. Therefore, evaluating the satisfaction of both patients and referring care providers with the spinal triage service is an important outcome, as the perceptions of both groups are crucial to the acceptance and adoption of this new and emerging role for PTs. Furthermore, unmet expectations in a health care encounter can be a source of reduced satisfaction. ${ }^{32}$ Certain patients, for example, may have expectations of seeing a surgeon rather than a physiotherapist. The objective of the present study was to evaluate patient and referring care provider satisfaction associated with a spinal triage service delivered by PTs in collaboration with orthopedic surgeons.

\section{Methods}

\section{Background: description of the spinal triage service}

The Spinal Triage Assessment Service (STAS) is a spinal assessment service located in a mid-size Canadian city and is a collaborative effort between a group of three orthopedic surgeons and PTs from a private rehabilitation clinic. The program was initiated to address an excessive number of referrals to the orthopedic surgeons of patients with low back-related conditions, the majority of whom did not require surgery. Prior to initiation of the program, the surgeons expressed frustration regarding how long people waited to see them (often over a year) and the high proportion of nonsurgical referrals in their caseloads. The surgeon group had an existing extensive working relationship with PTs from the rehabilitation clinic and approached the clinic to request help with their wait-list backlog and screening of subsequent new referrals pertaining to spine (mainly low back-related) conditions. All PTs involved in the STAS have completed advanced orthopedic training in the Canadian Orthopedic Syllabus with experience ranging from 5 to 30 years. At present, any people referred to the orthopedic surgeons for spinal problems are automatically re-routed to the PTs for screening. (Figure 1 shows the STAS referral and clinical pathways.)

The assessing PT discusses the findings of each assessment with the PT consultant via videoconferencing with the patient present (Figure 2). The clinical diagnosis and recommendations are determined jointly between the assessing PT and consultant PT through a collaborative reasoning approach $^{33}$ with input from the patient. A detailed report outlining the assessment findings, diagnosis, management recommendations, and any recommended further diagnostic tests is then sent to the referring health care providers and any other relevant care providers involved. The consultant PT had an extensive prior working relationship with the orthopedic surgeon group. 


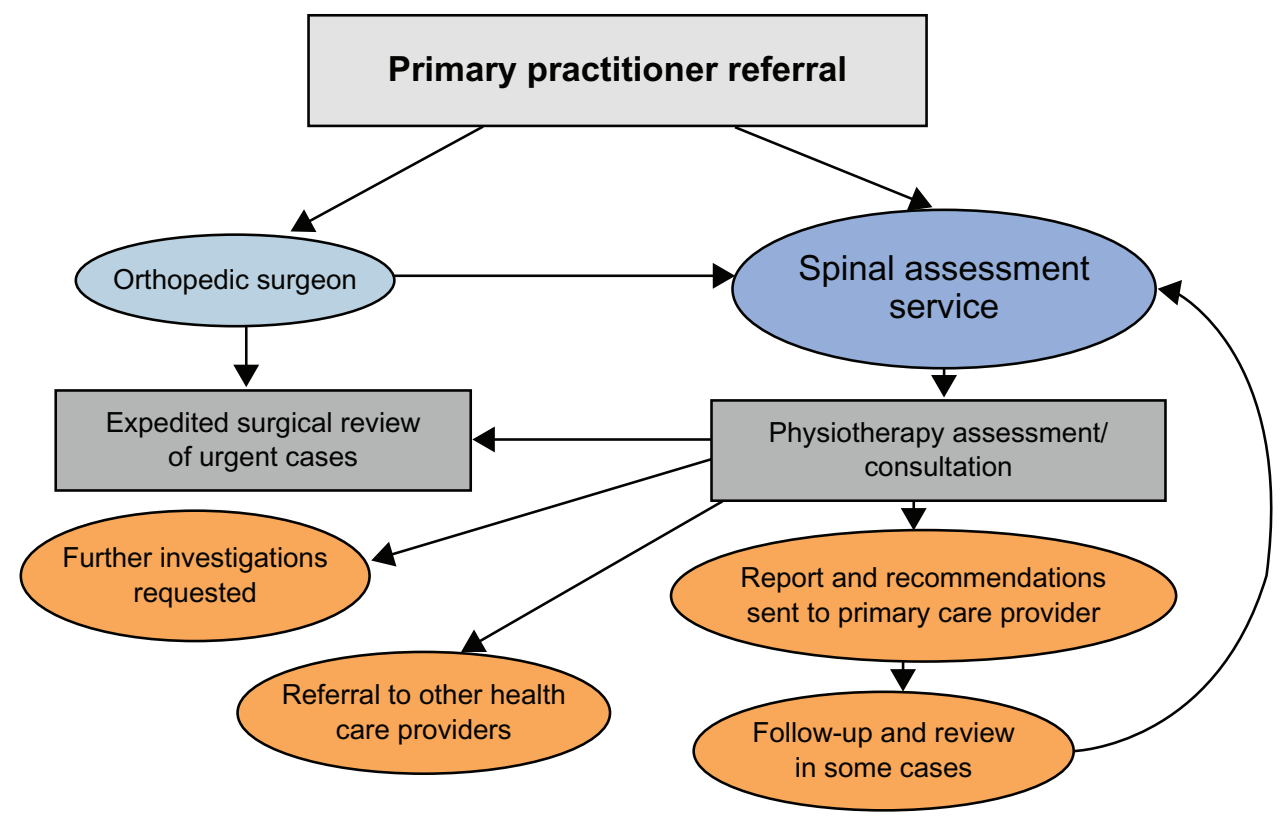

Figure I The Spinal Triage Assessment Service referral, assessment, and clinical pathways.

\section{Participants}

The participants in the study consisted of two groups: the patients referred to the service and the referring care providers. The patient participants of the study were recruited from a convenience sample of people referred to the triage program either directly from their primary care provider or via one of the triage program's orthopedic surgeons. The inclusion criteria included: patients referred to the triage program with primarily low back-related complaints, age $\geq 18$ years and $\leq 80$ years, and provision of informed consent. The exclusion criteria included: patients receiving third-party payer funding (ie, Workers' Compensation Board, or other) for their back-related complaints, patients with primarily neck (cervical spine) or mid-back

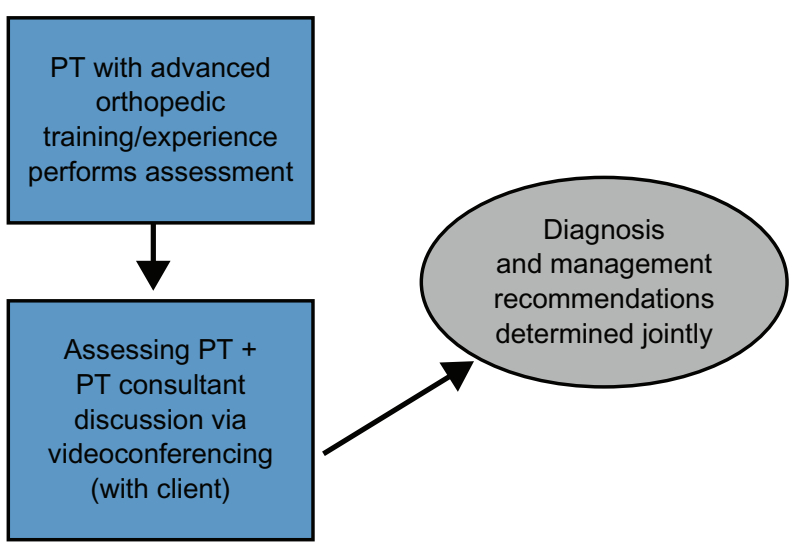

Figure 2 The Spinal Triage Assessment Service assessment process. Abbreviation: PT, physiotherapist. (thoracic spine) complaints, and people with language, reading, or comprehension barriers that would limit adequate completion of the study paperwork.

\section{Study design}

The satisfaction survey reported here was conducted as part of a prospective evaluation study that evaluated a number of multidimensional patient outcomes (ie, pain, function, quality of life) and biopsychosocial predictors of success with each outcome. The main study used a quasi-experimental one-group pretest-posttest design. ${ }^{34}$ This design represented the best option to evaluate this program given that there was no accessible and equivalent control group that could be used as a comparison. The "pretest" measures were derived from a paper-based survey that was completed before the participants underwent the triage assessment and also from a clinical classification tool completed by the assessing PT. The "posttest" evaluation of outcomes, including patient satisfaction surveys, was done at approximately 4 weeks following the assessment either through a mail or a password-protected online survey (as per the choice of the patient participant). Provider satisfaction surveys were faxed to referring health care providers with the completed assessment report. Reminders for completion of the patient participant follow-up surveys were done by phone or email prompts (up to three reminders approximately 1 week apart) on the basis of the tailored design method proposed by Dillman and colleagues. ${ }^{35}$ There were no reminders sent to referring care providers. This study was approved on ethical grounds by the Behavioral Ethics Board of the University of Saskatchewan. 


\section{Measures}

Patient satisfaction with the triage program was ascertained through two questions developed specifically for this purpose. The first question was: "How would you rate your satisfaction with the overall service you received from the health care providers at the [Spinal Triage Assessment Service]?" The second question was: "How would you rate your satisfaction with the recommendations that were made by the [Spinal Triage Assessment Service] health care providers to your doctor?" Possible responses were on a 5-point Likert scale (ie, "very satisfied," "somewhat satisfied," "neither satisfied nor dissatisfied," "somewhat dissatisfied," or "very dissatisfied"). Space was also provided for patient participants to list any comments regarding satisfaction.

Provider satisfaction with the report and recommendations were measured with one question: "How would you rate your satisfaction with the recommendations that were made by the [Spinal Triage Assessment Service] regarding your patient?" The providers chose from the same five response levels listed above and also had a space for general comments related to the triage program. The main cohort study also evaluated outcomes of pain, ${ }^{36,37}$ perceived function, ${ }^{38,39}$ and quality of life $\mathrm{e}^{40}$ through surveys done at baseline (ie, before the triage assessment) as well as at 4-week, 6-month and 12-month follow-up intervals. A variety of demographic, clinical, and psychosocial factors (eg, The Distress and Risk Assessment Method $)^{41}$ were also collected at baseline; however, only a selection of the baseline variables and outcome measures are presented in this paper in order to provide a more complete description of the sample.

\section{Analysis}

Differences in select demographic and clinical variables between patient participants and nonparticipant patients (ie, those who were eligible to participate but chose not to) as well as between patient participant responders and nonresponders at the posttest time point were evaluated with chi-square or Fisher's exact test for categorical variables, and independent samples $t$-test or Mann-Whitney U test (if there was a nonnormal distribution) for continuous variables. Frequencies and valid percents for the satisfaction survey question responses were calculated. All quantitative analysis was done with PASW (Predictive Analytics SoftWare) Statistics Mac version 18.0.

An inductive thematic analysis approach was applied to qualitatively describe the comments provided from the patient and health care provider satisfaction surveys.
A process of open and axial coding ${ }^{42,43}$ using NVivo 9 software was applied. During open coding, a constant comparative approach was used to group the codes into categories and identify themes. Axial coding was then done to look at the interrelationship of categories. ${ }^{42} \mathrm{~A}$ coding scheme was developed jointly and verified independently by two researchers by identifying, classifying, and labeling the primary patterns in the data. One of the researchers is a clinician academic with past experience in the spinal triage service and the second researcher is a nonclinician academic. Differences in coding between the researchers were resolved though discussion.

\section{Results}

\section{Participants versus nonparticipants}

The intake period of the study spanned 8 months (October 2009-June 2010). During this time period 198 people had an assessment through the triage program, 56 people were excluded (Table 1), and 27 people who met the inclusion criteria chose not to participate. This left a total of 115 patient participants and an overall response rate among those people that were eligible of $81.0 \%$ (115/142). Among study patient participants, 66/115 (57.4\%) opted to complete a mailed paper-based follow-up survey and 49/115 (42.6\%) chose to complete an online password-protected follow-up survey. There were no significant differences $(P>0.05)$ between patient participants and nonparticipants in age, gender, diagnosis, or management recommendations.

Of the 115 people who had agreed to participate in the study, 108/115 (93.9\%) actually completed the posttest survey. The only significant difference between the responders and nonresponders was "residence," with proportionately more nonresponders having an "urban" residence $(P=0.039)$. There were no significant differences between these groups with respect to age, sex, symptom duration,

Table I Reasons for exclusion from study

\begin{tabular}{ll}
\hline Reason & Frequency (\%) \\
\hline Age $>80$ or $<18$ & $7 / 56(12.5)$ \\
Third party payer funded ${ }^{\mathrm{a}}$ & $14 / 56(25.0)$ \\
Symptom location (ie, not lumbar spine region) & $13 / 56(23.2)$ \\
Did not attend & $4 / 56(7.1)$ \\
Assessment type ${ }^{\text {b }}$ & $6 / 56(10.7)$ \\
Otherc & $12 / 56(21.4)$ \\
\hline Notes: ${ }^{c}$ Workers' Compensation Board or other third-party insurance company; \\
btreatment direction assessment - person had already seen a surgeon, surgeon asking \\
for physiotherapists' opinion re further conservative treatment options; 'other - \\
includes scheduling conflicts, other medical (ie, medical urgency/emergency unrelated \\
to spine assessment, scheduled for joint replacement during study period).
\end{tabular}


income, education, diagnosis, and mode of follow-up (ie, paper based or internet based).

The provider satisfaction survey was sent to the referring care provider attached to the assessment report. The response rate was only $18.3 \%(21 / 115)$ despite attempts to increase the response rate via highlighting a request for completion of the survey at the beginning of the assessment report. There were no significant differences $(P>0.05)$ between patient age, gender, diagnostic category, and treatment recommendations (ie, PT or surgeon referral) between primary practitioner responders and nonresponders (determined by independent samples $t$-tests, chi-square tests or Fisher exact tests where appropriate). However, care providers of patient participants living in rural regions were significantly more likely to have responded (2/21 urban and 19/21 rural; $P=0.011)$.

\section{Description of study sample}

Descriptive statistics of demographic, employment, and general health variables of the study sample can be found in Table 2 (continuous demographic variables), Table 3 (categorical demographic and employment characteristics), and Table 4 (categorical general health variables). The median age of patient participants was 51 years, $48.7 \%$ were female, and the majority of participants were married $(74.8 \%)$. Most patient participants (55.6\%) had an educational attainment of more than grade 12 , an annual household income of greater than $30 \mathrm{~K}$ (Canadian dollars) $(81.6 \%)$, were employed (68.7\%), and had a "rural" residence $(70 \%)$. A sizeable proportion of the patient participants were farmers $(27.8 \%)$. The majority $(73.9 \%)$ of the sample had body mass index scores of greater than a "normal" range, ${ }^{44} 61.2 \%$ used to smoke or were current smokers, and $58.2 \%$ had two or more other chronic health conditions, with "other bone or joint problems" being the most prevalent condition reported (62.6\%). Approximately half $(50.8 \%)$ of patient participants were in the "at risk" Distress and Risk Assessment Method ${ }^{41}$ category, indicating psychological risk of depression and/or somatization, with $17.4 \%$ scoring as being "distressed" due to either somatic or depressive symptoms. Most patient participants $(79.2 \%)$ had "moderate" to "severe" perceived functional disability according to the Oswestry Disability Questionnaire categorized scores. ${ }^{38,39}$

Clinical descriptors of the study sample can be found in Table 5. The patient participants reported having relatively long total duration of symptoms $(74.8 \%>24$ months $)$ and current episode duration. The majority of these participants had attempted a variety of noninvasive or conservative treatment modalities in the past, including medication, massage therapy, chiropractic, and physiotherapy with relatively few $(3.5 \%)$ reporting having had past surgical intervention for their back problems. The majority of patient participants also reported having below knee symptoms $(59.1 \%)$, indicating potential nerve root involvement. A summary of the categorization of clinical features with a clinical classification tool (Appendix A) completed by the assessing PT can also be found in Table 5. The majority of patient participants were classified as having a "problem in back" (93.9\%); however, a relatively high proportion of participants were classified as having "medical" (9.6\%) and "spinal cord/cauda equina" (4.3\%) presentations. Similarly, categorization according to the low back pain triage categories demonstrated relatively high proportions of "nerve root problems" (47.0\%) and "serious spinal pathology" (7.0\%). Further PT treatment was recommended in the majority of cases $(63.5 \%)$ and "referral to the surgeon" was made in $20 \%$ of cases.

\section{Quantitative results}

Table 6 presents a summary of the quantitative responses of the patient participants and referring care providers. The majority of patient participants were "very satisfied" with the service $(65.7 \%)$ and with the recommendations that were made $(54.6 \%)$. No participants were "very dissatisfied" with either the service or recommendations. A total of $83 / 108(76.9 \%)$ of patient participants were either "very" or "somewhat satisfied" with both the service and

Table 2 Demographics of study sample (continuous variables)

\begin{tabular}{|c|c|c|c|c|c|c|}
\hline Variable & Min & $\operatorname{Max}$ & Mean & SD & Median & IQR \\
\hline Age (years) & 20 & 79 & 51.69 & 13.543 & 51.00 & $43.0-62.0$ \\
\hline Symptom total duration (months) & $\mathrm{I}$ & 480 & 138.94 & 128.778 & 108.00 & $28.5-240$ \\
\hline Current episode duration (months) & I & 408 & 39.54 & 72.880 & 10.00 & $4.0-36.0$ \\
\hline Body mass index (kilogram/meter ${ }^{2}$ ) & 18.75 & 58.39 & 28.84 & 6.718 & 27.32 & $24.4-31.6$ \\
\hline
\end{tabular}

Abbreviations: Min, minimum; Max, maximum; SD, standard deviation; IQR, interquartile range. 
Table 3 Demographic and employment characteristics (categorical variables)

\begin{tabular}{|c|c|}
\hline Variable & Frequency (\%) \\
\hline \multicolumn{2}{|l|}{ Age quartiles } \\
\hline$<43$ yrs & $29 / 115(25.2)$ \\
\hline $43-51$ & $31 / I I 5(27.0)$ \\
\hline $52-62$ & $31 / 115$ (27.0) \\
\hline$>62$ & $24 / 115(20.9)$ \\
\hline Age $<50$ yrs & $53 / 115(46.1)$ \\
\hline Female & $56 / 115(48.7)$ \\
\hline \multicolumn{2}{|l|}{ Marital status } \\
\hline Married & $86 / 115(74.8)$ \\
\hline Separated & I/I I5 (0.9) \\
\hline Divorced & $8 / 115(7.0)$ \\
\hline Widowed & $4 / 115(3.5)$ \\
\hline Never married & $16 / 115$ (13.9) \\
\hline \multicolumn{2}{|l|}{ Education } \\
\hline Did not complete grade 12 & $21 / 115(18.3)$ \\
\hline Completed grade 12 & $30 / 115(26.1)$ \\
\hline Trade school & $34 / 115$ (29.6) \\
\hline Some university & $19 / 115(16.5)$ \\
\hline University degree & $9 / 115(7.8)$ \\
\hline Graduate degree & $2 / 115(1.7)$ \\
\hline \multicolumn{2}{|l|}{ Income } \\
\hline$<15 \mathrm{~K}$ & $10 / 109(9.2)$ \\
\hline $15-29,999 \mathrm{~K}$ & $10 / 109(9.2)$ \\
\hline $30-59,999 \mathrm{~K}$ & $38 / 109(34.9)$ \\
\hline $60 \mathrm{~K}-99,999$ & $31 / 109(28.4)$ \\
\hline$\geq 100 \mathrm{~K}$ & $20 / 109(18.3)$ \\
\hline \multicolumn{2}{|l|}{ Employment } \\
\hline Paid full time & $62 / 115(53.9)$ \\
\hline Paid part time & $17 / 115(14.8)$ \\
\hline Unemployed & $5 / 115(4.3)$ \\
\hline Housework & $9 / 115$ (7.8) \\
\hline Disabled & $4 / 115(3.5)$ \\
\hline Student & $2 / 115(1.7)$ \\
\hline Retired & $16 / 115(13.9)$ \\
\hline Not working due to back pain & $22 / 115(19.1)$ \\
\hline Back pain caused by work & $42 / 115(36.5)$ \\
\hline Rural $^{a}$ & $77 / 115$ (70.0) \\
\hline Farmer & $32 / 115(27.8)$ \\
\hline
\end{tabular}

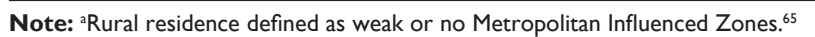

the recommendations. The vast majority of referring care providers who responded to the survey $(90.5 \%)$ were "very satisfied" with the report and recommendations; however, given the low response rate $(18.3 \%)$, these results should be interpreted with caution.

\section{Qualitative results}

Sixty-one patient participants and 14 referring care providers provided comments on a diverse range of themes. Comments were grouped into the following general themes:
Table 4 General health and other variables

\begin{tabular}{|c|c|}
\hline Variable & Frequency (\%) \\
\hline \multicolumn{2}{|l|}{ Smoking status } \\
\hline Never smoked & $44 / 115(38.3)$ \\
\hline Used to smoke & 45/II 5 (39.1) \\
\hline Current smoker & $26 / 115(22.6)$ \\
\hline \multicolumn{2}{|l|}{$\mathrm{BMI}^{\mathrm{a}}$} \\
\hline Normal & $30 / 115(26.1)$ \\
\hline Overweight & $44 / 115(38.3)$ \\
\hline Grade I obesity & $26 / 115(22.6)$ \\
\hline Grade 2 obesity & $8 / 115(7.0)$ \\
\hline Grade 3 obesity & $7 / 115(6.1)$ \\
\hline \multicolumn{2}{|l|}{ Other health } \\
\hline Other bone or joint problems & $72 / 115(62.6)$ \\
\hline Headaches & $42 / 115(36.5)$ \\
\hline Stomach or digestive problems & $29 / 115(25.2)$ \\
\hline Lung or breathing problems & $16 / 115(13.9)$ \\
\hline Hypertension & $14 / 115$ (12.2) \\
\hline Heart problems & $12 / 115(10.4)$ \\
\hline Diabetes & $9 / 115(7.8)$ \\
\hline Other & $18 / 115(15.7)$ \\
\hline \multicolumn{2}{|l|}{ Number of other health problems } \\
\hline 0 & $12 / 115(10.4)$ \\
\hline I & 36/II5 (31.3) \\
\hline 2 & $42 / 115(36.5)$ \\
\hline 3 or more & $25 / 115(21.7)$ \\
\hline \multicolumn{2}{|l|}{ DRAM } \\
\hline Normal & $37 / 115(32.2)$ \\
\hline At risk & $58 / 115(50.4)$ \\
\hline Distressed, somatic & $8 / 115(7.0)$ \\
\hline Distressed, depressive & $12 / 115(10.4)$ \\
\hline \multicolumn{2}{|l|}{ ODQ } \\
\hline Minimal $(0-20)$ & $16 / 115(13.9)$ \\
\hline Moderate $(21-40)$ & $60 / 115(52.2)$ \\
\hline Severe $(4 I-60)$ & $31 / 115(27.0)$ \\
\hline Extreme disability $(6 \mathrm{I}-80)$ & $8 / 115(7.0)$ \\
\hline
\end{tabular}

Notes: aBMI: normal 18.5-24.9, overweight 25-29.9, grade I obesity 30-34.9, grade 2 obesity $35-39.9$, grade 3 obesity $\geq 40,3^{36}$ there were no participants in the $80-100$ category.

Abbreviations: BMI, body mass index; DRAM, Distress and Risk Assessment Method; ODQ, Oswestry Disability Questionnaire.

positive, negative, or neutral (pertaining to the spinal triage service or process) or "other" (not pertaining to the spinal triage service). The participant and provider comments are reported in greater detail below. A summary of patient and provider general themes and subthemes can be found in Table 7.

\section{Patient comments: positive Understanding the problem/diagnosis}

The following four interrelated subthemes were grouped under the specific theme of "understanding the problem": accurate diagnosis, relief, hope for the future, and role of the PT consultant. Patient participants stated that by going 
Table 5 Clinical descriptors of study sample

\begin{tabular}{|c|c|}
\hline Variable & Frequency (\%) \\
\hline \multicolumn{2}{|l|}{ Back pain duration } \\
\hline $0-6$ months & $15 / 114(13.2)$ \\
\hline $7-12$ months & $5 / 114(4.4)$ \\
\hline 13-24 months & $8 / 114(7.0)$ \\
\hline$>24$ months & $86 / 114$ (74.8) \\
\hline \multicolumn{2}{|l|}{ Back pain, current episode } \\
\hline $0-6$ months & $46 / 115(40.0)$ \\
\hline $7-12$ months & $19 / 115(16.5)$ \\
\hline 13-24 months & $18 / 115(15.7)$ \\
\hline$>24$ months & $32 / 115(27.8)$ \\
\hline \multicolumn{2}{|l|}{ Past treatment: } \\
\hline Medication & $75 / 115(65.2)$ \\
\hline Massage therapy & $72 / 115(62.6)$ \\
\hline Chiropractic & $69 / 115(60.0)$ \\
\hline Physiotherapy & $63 / 115(54.8)$ \\
\hline Exercise therapy & $39 / 115$ (33.9) \\
\hline Acupuncture & $30 / 115(26.1)$ \\
\hline Surgery & $4 / 115(3.5)$ \\
\hline \multicolumn{2}{|l|}{ Radiating leg symptoms } \\
\hline Absent & $16 / 115(13.9)$ \\
\hline Above knee & $31 / 115(27.0)$ \\
\hline Below knee & $68 / 115(59.1)$ \\
\hline \multicolumn{2}{|l|}{ Diagnosis $^{a}$} \\
\hline Problem in back & $108 / 115$ (93.9) \\
\hline Medical & $11 / 115(9.6)$ \\
\hline Mechanical/degenerative other body part & $5 / 115(4.3)$ \\
\hline Spinal cord/cauda equine & $5 / 115(4.3)$ \\
\hline \multicolumn{2}{|l|}{ Back pain triage } \\
\hline Nerve root problem & $54 / 115(47.0)$ \\
\hline Nonspecific/mechanical spine & $48 / 115(41.7)$ \\
\hline Serious spinal pathology & $8 / 115(7.0)$ \\
\hline Not spine related & $5 / 115(4.3)$ \\
\hline \multicolumn{2}{|l|}{ Nerve root source } \\
\hline None & $52 / 115(45.2)$ \\
\hline Stenotic & $35 / 115(30.4)$ \\
\hline Discogenic & $28 / 115(24.3)$ \\
\hline \multicolumn{2}{|l|}{ Treatment recommendations } \\
\hline Referral to surgeon (any) & $23 / 115(20.0)$ \\
\hline Urgent referral to surgeon & $16 / 115$ (13.9) \\
\hline Surgeon referral + PT treatment & $6 / 115(5.2)$ \\
\hline Emergency referral to surgeon & $1 / 115(.9)$ \\
\hline Referral to another specialist ${ }^{\mathrm{b}}$ & $11 / 115(9.6)$ \\
\hline PT Treatment (any) & $73 / 115(63.5)$ \\
\hline PT Treatment (only) & $67 / 115(58.3)$ \\
\hline \multicolumn{2}{|l|}{ Imaging and diagnostic tests ${ }^{\mathrm{a}}$} \\
\hline Any imaging or other diagnostic tests ${ }^{c}$ & $38 / 115(33.0)$ \\
\hline Advanced imaging (ie, CT, MRI) & $31 / 115(27.0)$ \\
\hline X-rays & $8 / 115(7.0)$ \\
\hline No further follow-up & $2 / 115(1.7)$ \\
\hline Other ${ }^{d}$ & $7 / 115(6.1)$ \\
\hline
\end{tabular}

through the spinal triage assessment service they obtained a greater understanding of their problem(s) and appreciation for an "accurate diagnosis" was expressed:

I think they hit the nail on the head as far as diagnosing my problem, as when I follow their instructions, the outcome is just as I have been told it would be. And also, triggers are exactly what they have said they would be. (816)

Furthermore, a sense of psychological "relief" was expressed by participants related to receiving a diagnosis and being able to make sense of their symptoms:

Thank you for me finally getting an accurate diagnosis.

My doctors are following pain management protocols and

I am slowly feeling less pain and anxiety about not having any answers. (8201)

It's been a huge relief to find out what is going on with my back. At least somebody knows what the heck they are doing. (2157)

Patient participants also described overcoming a sense of hopelessness because of receiving a greater understanding of their problem and the potential to find "solutions" or strategies to manage their symptoms:

I am pleased that assessment service is moving forward with trying to figure out what is the problem with my back and legs and arms and maybe a solution to help me move on with my life and how I can control the pain. (6178)

Finally, the role of the PT consultant in the assessment process was thought to enhance participants' understanding of their diagnosis/problem and the management recommendations arising from the assessment:

My assessment at the [STAS] was very thorough and I really appreciated being able to discuss my case and treatment program with [consultant PT] during my appointment. (4200)

\section{Communication and empathy}

Communication is a two-way process that involves both talking and listening. Being "heard" through effective attentive listening was identified by one participant with longstanding pain as being an important aspect of the spinal assessment service:

I have been in a considerable amount of pain for approximately 26 years. The doctors [ie, PTs] with [the spinal assessment service] are the first to actually listen to what I had to tell them. (1820) 
Table 6 Patient and referring health care provider satisfaction

\begin{tabular}{|c|c|c|c|c|}
\hline Variable/ltem & Very satisfied & $\begin{array}{l}\text { Somewhat } \\
\text { satisfied }\end{array}$ & $\begin{array}{l}\text { Neither satisfied } \\
\text { nor dissatisfied }\end{array}$ & $\begin{array}{l}\text { Somewhat } \\
\text { dissatisfied }^{2}\end{array}$ \\
\hline Participant satisfaction with service & $71 / 108(65.7)$ & $26 / 108(24.1)$ & $9 / 108(8.3)$ & $2 / 108(1.8)$ \\
\hline Participant satisfaction with recommendations & $59 / 108(54.6)$ & $27 / 108(25.0)$ & $22 / 108(20.4)$ & $0 / 108(0)$ \\
\hline Provider satisfaction with report and recommendations & $|9 / 2|(90.5)$ & $|/ 2|(4.8)$ & $|/ 2|(4.8)$ & $0 / 2 I(0)$ \\
\hline
\end{tabular}

Note: aNo patients or providers chose "very dissatisfied."

Empathy, through acknowledging and understanding, was also identified as a key component of the spinal assessment encounter:

I was very pleased with the way the people of [the STAS] treated me, with deep concern and excellent understanding, and they talked me through things very well. (8063)

\section{Customer service}

The vast majority of comments provided on the satisfaction surveys related to aspects of customer service. Several participants expressed gratitude for both the service provided and for the recommendations that were made. Furthermore, identifying nonspinal pathology and redirecting patients to appropriate management pathways is an important role of the triage service. One participant expressed their gratitude for the physiotherapists referring them on to a surgeon for review of their hip pathology:

I am grateful that I went to the [STAS] ... because of that, I was able to see a surgeon who has informed me that I need TWO new hips in order to be free from pain and able to lead a normal life that I used to enjoy. (2711)

\section{Efficiency of care}

The triage service was initially started to help the participating surgeons manage and reduce their wait-lists. This potential to improve the efficiency of traditional management and referral pathways through a service such as the STAS was identified by several participants:
I think the [STAS] is a good practice to follow to help doctors to speed the system up. (6143)

I've checked the internet on wait times and was worried thing would take longer, but I am impressed with how fast things have progressed. (2061)

\section{Provider comments: positive Patients are satisfied}

Provider satisfaction appears to have been heavily influenced by the satisfaction of the patients they referred to the triage service:

I have had no unhappy/dissatisfied patients back from you!

Thank you for your help! (2765)

One provider also expressed that patient/client satisfaction helps to facilitate "buy in" or acceptance of the recommended management strategies:

Client satisfaction also helps when discussing and promoting the programs suggested. This client very happy with service ... (6178)

\section{Efficiency and detail}

Quick assessment times and thorough assessment reports were cited by providers as being aspects of the service they were pleased with:

My patients are happy with quick appointment times. (6264)

Very thorough. Quick response to see patient. Detailed letter re patient. (5013)

Table 7 Summary of qualitative themes from patient and provider satisfaction surveys

\begin{tabular}{llll}
\hline Respondent & Positive & Negative & Neutral/Other \\
\hline Patient & Understanding the problem/diagnosis & Lack of detail & Symptoms \\
& $\begin{array}{l}\text { Communication and empathy } \\
\text { Customer service }\end{array}$ & Time to follow-up & Limited access to care \\
& Efficiency of care & Cost of assessment/treatment & Limited access to care \\
Provider & Patients are satisfied & Recommendations do not account for limited & \\
& rural health services access & & \\
& Efficiency and detail & & \\
& Gives direction of care pathway & &
\end{tabular}




\section{Gives direction for care pathway}

In addition to aspects of efficiency and detail, providers also indicated that the recommendations provided in the assessment report were a useful guide to their management approach.

Your feedback is very helpful in management of patients and most of my patients are very satisfied. (5510)

I am always happy to have the help of STAS for my patients.

I do not have anywhere near as ready access to any other physiotherapy group and your assessments are always timely, thorough and very helpful in getting the ball rolling in regards to further treatment. (668)

Providers also commented on the difficulties and frustrations that can be associated with the management of people with chronic back problems.

Back pain/sciatica is a very frustrating problem for everyone, including physicians and patients. I feel that the correct pathway of care is being followed [and made available to patient] - very satisfied. (6206)

Very good place to refer severe back pain patients that do not have anything to gain from surgery. (0353)

The above comments reinforced the notion that the triage service serves not only the patients, but the referring care providers as well.

\section{Patient comments: negative Lack of detail}

The most common negative comment related to the spinal triage process and recommendations was associated with a desire to have been provided with greater detail, particularly if conservative management was recommended:

I thought the exact regimen would be provided to the physiotherapist to better match the treatment with my personal needs. (3326)

I expected more detail regarding my rehabilitation process would be provided. (1574)

Also, one participant expressed that even after undergoing the triage assessment, they still had concerns about their condition and how to manage it:

I do not seem to know what is actually wrong with me. Soft tissue damage, how to treat, how to prevent, how to relieve pain, what is wrong? I need to know. (6444)

\section{Time to follow-up}

The typical protocol for the spinal assessment process involves a discussion by the assessing PT and/or consulting
PT with the patient at the time of the assessment regarding the assessment findings and the management plan. However, according to a couple of participants, deviations from this protocol may have resulted in delays in being informed of the recommendations:

I was disappointed that the information took so long to get back to me but I also realize that things do some times take longer than one would like at times. (6742)

I was hoping to get some recommendations earlier than 4 (weeks) after my assessment. (6508)

\section{Costs of assessment/treatment recommendations}

One participant expressed frustration that the PT treatment recommendations stemming from the assessment would not be publically funded, given that a consultation with a medical specialist would have been covered under provincial health services:

I was told that in order to see the specialist that I needed to see the [STAS] staff first ... based on their assessment I have to start physio, but THIS has to be paid for by myself ... If this is now the norm for medical treatment, why not covered under health care??? (4402)

The STAS is delivered by a private rehabilitation clinic and there is a standard PT assessment fee which patients referred to the service are informed of when their appointment time is booked. Most people referred to the service have additional health insurance through which they are able to obtain reimbursement for this service. People who state they cannot pay are not denied access to the assessment service. If PT treatment is recommended, the decision of where to attend treatment is left up to the patient and referring care provider. PT services in the Canadian province where the STAS is located are offered through both private and publically funded facilities (although typically with greater wait times for the latter).

\section{Provider comments: negative}

\section{Recommendations do not account for limited} rural health services

The only provider comment that was coded as "negative" pertained to management recommendations that do not consider the local context with regard to access to services:

The recommendations sometimes do not take restrictions and lack of services that we have to deal with in rural practice into consideration. (4757)

Typically, the management recommendations made in the triage assessment reports are presented as the "best case" 
or "ideal" treatment pathway, thus the local availability or accessibility of services may not necessarily be taken into account.

\section{Patient comments: neutral}

Comments that were coded as "neutral" typically involved patient participants providing an update related to recommendations stemming from the assessment service and included: awaiting further follow-up with their referring care provider, waiting to undergo or to receive results of further diagnostic tests, or simply awaiting the "outcome" of treatment or management recommendations.

\section{Patient comments: other Symptoms}

Many patient comments coded under "symptoms" were unrelated to the assessment process itself, but were nevertheless important to consider given the longstanding chronic pain that many in the group experienced. General frustration with persisting or worsening symptoms as well as a lack of improvement was a common theme expressed by participants:

I lay down 23 hours in the day and the pain is bearable but when I stand or sit the pain is excruciating. I don't want to be in bed all the time ... I am doing the recommendations faithfully but haven't any results yet. I realize physio takes time and am trying to be patient. (6508)

Others were resigned to the likelihood that there is no "fix" for their problem:

I feel that the health care system can't give me any answer at present as to control or fixing my back problems. (2427)

Recognition of the biopsychosocial nature or "mindbody" aspects of pain, especially chronic pain, was made by some participants:

Treatment was a big help and I'm very thankful. But when one is on their own and alone it is hard for that person to heal and only causes more pain and stress! This is very much also a battle for the mind as well as my body. (4248)

How I feel day to day changes - physically and mentally (need to find results or solutions for both). Not much as of yet. (7868)

Finally, the importance of other regions of pain or other health problems/comorbidities was stated by others:

I have a thoracic element which causes as much grief in the shoulders and neck as the sciatic situation. (8147)

\section{Limited access to care}

Concern regarding the ability to access recommended treatment services - particularly physiotherapy services, due to cost, wait times, or location - was an issue raised by some participants:

I haven't had any physical therapy yet ... [there is] a long waiting list [and I] have to pay. It is expensive. Will see what happens. (4084)

I only have access to rural services and this can be very frustrating. (4757)

\section{Provider comments: other}

\section{Limited access to care}

This frustration with limited access to health services in rural areas was reinforced by care providers as well (see comments 668 and 4757 above).

\section{Discussion}

The aim of this study was to explore patient and referring care provider satisfaction associated with a spinal triage service delivered by PTs in collaboration with orthopedic surgeons. The quantitative results of the patient satisfaction survey demonstrated very high levels of satisfaction with the service and slightly less satisfaction with the recommendations that were made. Satisfaction of referring care providers with the recommendations and report was also high, but given the low response rate, these results should be interpreted with caution.

The high levels of patient satisfaction mirror results from other studies examining physiotherapists in similar triage roles for orthopedic conditions where satisfaction with PT-delivered care was either equivalent to ${ }^{31,45}$ or exceeded ${ }^{19}$ that provided by orthopedic surgeons. Blackburn et al examined the level of satisfaction of referring physicians with a physiotherapy-led spinal triage clinic for low back pain in Australia. The satisfaction quantitative survey used by this group covered dimensions of satisfaction with wait times, quality and timeliness of feedback, and overall management of patients. ${ }^{31} \mathrm{We}$ are unaware of other studies that have examined the satisfaction of referring care providers and patients using both quantitative and qualitative methods in relation to PTs in orthopedic triage roles.

Satisfaction is a multidimensional concept. For example, people or users of a service can be satisfied with one aspect of care, but not with another. ${ }^{46,47}$ Common dimensions incorporated in standardized satisfaction measures used in health care settings include: interpersonal manner, 
technical quality, accessibility and convenience, finances, efficacy and outcomes, continuity, physical environment, and availability. ${ }^{47,48}$ Although there are several standardized multidimensional quantitative patient satisfaction surveys described in the literature, ${ }^{3,47,49-52}$ the participant and provider satisfaction surveys used in this study were specifically developed on the basis of identified stakeholder needs and the nature of the triage service. Other studies examining satisfaction with PTs in similar triage roles have either had to modify existing standardized patient visit questionnaires ${ }^{19,45}$ or create their own to suit their unique purposes. ${ }^{31,53}$ Although the use of a nonvalidated tool may be perceived by some as a study limitation, there are several reasons why we opted to develop global satisfaction measures for both participants and referring care providers that included satisfaction with the service and the resulting recommendations. Firstly, the assessment report and detailed recommendations are a main output of the spinal triage program and the program is meant to serve both the referred patients and the care providers that refer them. Secondly, the satisfaction survey reported in this paper was one of several patient self-reported outcome measures examined in a larger ongoing cohort study, so a longer multidimensional tool may have added to responder burden and perhaps impacted the response rate. Finally, had a standardized quantitative survey been used, we may not have garnered the extensive and varied comments that we were able to explore through qualitative analysis.

The combination of open-ended with closed-ended questions is recommended to provide a fuller understanding of satisfaction and experiences. ${ }^{46,47,54}$ Slade and Keating suggest that patient "satisfaction" surveys are different than patient "experience" surveys: "Patient satisfaction questionnaires ask closed-ended questions and assess factors that researchers and care-givers regard as important. Patient experience surveys ask open-ended questions that regard health care users, especially those with chronic conditions, as the experts by virtue of their experience in assessing service quality." ${ }^{54}$ The satisfaction surveys used in this study included a space for comments, thus allowing for an examination of the "experience" of patients and referring care providers with the STAS. Analysis of these comments revealed a variety of themes related to satisfaction or dissatisfaction with the service as well as issues that were not directly related to the service and that were coded in an "Other" category. Comments that were coded in the "Other" category may be important environmental (eg, access to services) or individual contextual factors (eg, presence of comorbidities) that have the potential to impact other patient-relevant outcomes such as pain, function, and quality of life.
We propose that a triage assessment program delivered by PTs can be viewed as a complex intervention that has the potential to impact a wide range of patient (and provider) outcomes, including satisfaction. Complex interventions may contain a number of different elements that act independently or interdependently, thus it is difficult to identify precise mechanisms that contribute to outcomes..$^{55} \mathrm{In}$, as of yet, unpublished work evaluating the spinal triage service, we have found there was mean overall short-term improvement in self-reported physical general health and pain measures. Patient education and reassurance may be an important reason for short-term improvements in these outcomes.

Upwards of $50 \%$ of back pain patients presenting to primary care suspect that they have serious pathology. ${ }^{13,56}$ People who experience pain, particularly when the precise cause cannot be determined, often feel hopeless and helpless. Additionally, the inability to obtain timely or effective relief for their pain may result further in depression and anxiety. ${ }^{57}$ This, in turn, can lead to increased perceived pain and disability. ${ }^{58}$ Feelings of uncertainty and insecurity regarding fear of the unknown (ie, having a diagnosis of "nonspecific low back pain," or having no clear diagnosis at all) also have the potential to hamper any attempts at treatment and potential recovery. ${ }^{59}$

A systematic review of qualitative and quantitative studies examining patient expectations for back-pain treatment echoed many of the themes found in this study relating to diagnosis, education, and interpersonal management. ${ }^{60}$ Furthermore, patients expect confirmation from health care providers that their pain is real and that providers will listen, be respectful, and include them in the decision-making process. Participant/patient comments acknowledged that learning about their problem was related to feeling less pain and anxiety about not having any answers. Both the assessing and consulting PT in the triage assessment play an important role in reassuring the patient about their symptoms and how they may relate to potential underlying conditions. Also, given that the main output of the assessment is a detailed report that outlines a plan of action for subsequent management, investigations, and follow-up this likely gives users of the service a greater sense of certainty and control. However, Linton and colleagues ${ }^{61}$ propose that reassurance in the form of education alone is likely not enough to positively affect pain outcomes and, instead, suggest that expressing empathy may be a critical feature in reassurance. Health care providers can express empathy through acknowledging and showing understanding of what the patient is experiencing with elements of respect and acceptance. ${ }^{62}$ 
Empathetic communication was expressed by participants as an important feature of the spinal triage service. The role of reassurance in interactions between health care providers and patients with chronic pain is a complex process that requires further study. ${ }^{61}$ Further research in this area may help to elucidate the role of reassurance and empathy in the spinal triage assessment process and other potential mechanisms for why improvements in outcomes occur.

The triage service is a model of care that operates at the interface between primary and secondary levels of care; therefore, the characteristics of patients referred to this service and the patterns of referral sources potentially reflect unmet needs at the primary care level. Back pain is known to be a common reason for seeking care at the primary care level. ${ }^{63,64}$ Comments from the referring care providers and participants indicated that back pain and sciatica are frustrating and complex problems to deal with and that the triage program provides a means for more efficient access to appropriate care. Care providers and participants also alluded to problems with access to care due to lack of services in rural areas, as well as costs and wait times related to recommended treatment pathways. Further study is needed to more fully understand the impact that a spinal triage program may have on meeting the needs and perhaps easing the burden of primary care providers. Also, the impact of reduced access to local health care services on participant outcomes, especially in rural and remote areas, is an important area for further research.

This study has several potential sources of bias and limitations that should be considered. The primary limitation is the lack of a control or comparison group. The triage service represents a substantial shift in the participating surgeons' clinical practice, at least pertaining to management of spinal problems. As this study was initiated 7 years after the triage service began, access to a "usual" care or comparison group managed exclusively by the surgeons was not possible. Thus, we were not able to compare satisfaction (or other outcome measures including wait times) between those managed by PTs versus a traditional referral pathway to the surgeon. Selection bias due to nonresponse or loss to follow-up may also impact the results of this study. Although there was a high participant response rate, only a small proportion of referring care providers responded. Determination of a reasonable response rate for surveys of this type is not well established. ${ }^{35}$ Many providers referred more than one patient/participant to the study. Thus, they may have only completed and returned one survey, despite instructions that stated the surveys were meant to be specific to the report/recommendations for each respective patient.
Also, unlike the participant surveys, reminders for completion of the provider surveys were not part of this study's protocol. A common measurement error related to satisfaction surveys is high undifferentiated levels of satisfaction. ${ }^{47}$ The distribution of satisfaction scores highly skewed or clustered in only a few responses at the top of the possible range is a potential problem with global measures (such as the ones used in this study) and the use of a multidimensional tool may have resulted in higher variability in satisfaction scores. Another limitation is that the qualitative analysis was done on an ad hoc basis due to the volume and variety of comments on the surveys. Although a wide variety of themes were identified, this study used primarily descriptive qualitative analysis. Further qualitative research using more focused and rigorous methods would help to corroborate, refute, or expand the exploratory results of this study. A final limitation is that information on wait times was not collected.

\section{Conclusion}

A spinal triage program delivered by PTs represents a shift in traditional practice boundaries that may affect patient and referring care provider expectations. Evaluating the satisfaction of both patients and referring care providers is, therefore, an important outcome, as the perceptions of both groups are crucial to the acceptance and adoption of this new and emerging role for PTs.

The quantitative results of the patient participant satisfaction survey demonstrated very high levels of satisfaction with the service and slightly less satisfaction with the recommendations that were made. Satisfaction of referring care providers with the recommendations and report was also high, but given the low response rate, these results should be interpreted with caution. Exploratory qualitative analysis of patient and provider comments revealed a diverse range of themes related to satisfaction or dissatisfaction with the service. Positive themes identified by the patients and providers pertaining to the service involved aspects of diagnosis, reassurance, customer of service, efficiency of care, and guidelines for direction of a care pathway. Negative themes related to the service included perceived lack of detail, time to follow-up, and issues related access to services due to cost or lack of local availability. Other themes identified that were not directly related to the service involved persisting or chronic symptoms, presence of comorbidities, and limited access to health care. These "other" issues may be important contextual factors that have the potential to impact other patient relevant outcomes such as pain, function, and quality of life. 


\section{Acknowledgments}

The authors are grateful to the surgeons and physiotherapists associated with the STAS for their support of this project. We are also thankful to Cindy Robb for her assistance with data entry and study administration.

\section{Disclosure}

Brenna Bath was supported by the following funders during the course of this research: Canadian Institutes of Health Research (CIHR) Fellowship in Knowledge Translation, Public Health and the Agricultural Rural Ecosystem CIHR Graduate Training Program, and the Western Regional Training Centre for Health Services Research CIHR Graduate Training Program. Operational funding for this research was provided by Bourassa and Associates Rehabilitation Centre, Saskatoon, Saskatchewan, Canada.

\section{References}

1. Sanmartin C, Berthelot JM. Access to health care services in Canada. JanDec 2005. Ottawa: Statistics Canada; 2006; Catalogue 82-575-XIE.

2. Carrière G, Sanmartin C. Waiting time for medical specialist consultations in Canada, 2007. Ottawa: Statistics Canada; 2010; Catalogue no 82-003-XPE.

3. Goldstein MS, Elliott SD, Guccione AA. The development of an instrument to measure satisfaction with physical therapy. Phys Ther. 2000;80:853-863.

4. Barua B, Rovere M, Skinner BJ. Waiting your turn. Wait times for health care in Canada. Vancouver: 2010 report. The Fraser Institute; 2010:20.

5. Ackerman IN, Graves SE, Wicks IP, Bennnell KL, Osborne RH. Severely compromised quality of life in women and those of lower socio-economic status waiting for joint replacement surgery. Arthritis and Rheum. 2005;53(5):653-658.

6. Braybrooke J, Ahn H, Gallant A, et al. The impact of surgical wait time on patient-based outcomes in posterior lumbar spinal surgery. Eur Spine J. 2007;16(11):1832-1839.

7. Hadjistavropoulos H, Snider B, Hadjistavropoulos T. Anxiety in older persons waiting for cataract surgery: Investigating the contributing factors. Can J Aging. 2001;80(1):97-111.

8. Sarro A, Rampersaud YR, Lewis S. Nurse practitioner-led surgical spine consultation clinic. J Adv Nurs. 2010;66(12):2671-2676.

9. Hadlow AT. Back pain: A problem of referral. J Bone Joint Surg Br. 2003;85-B(Suppl III):208.

10. MacKay C, Canizares M, Davis A, Badley E. Health care utilization for musculoskeletal disorders. Arthritis Care Res. 2010;62(2): 161-169.

11. Canizares M, MacKay M, Davis A, Mahomed N, Badley E. Orthopaedic surgery in Ontario in the era of the wait time strategy. Part 1: Pattern of use of orthopaedic surgeon services in Ontario 2005/06 including surgical trends 1992/93-2005/06. Ontario: Arthritis Community Research and Evaluation Unit; 2006.

12. Mayman D, Yen D. Maximizing use of a surgical clinic for referrals of patients having back problems. Can J Surg. 1999;42:117-119.

13. Waddell G. Diagnostic triage. In: The Back Pain Revolution. 2nd ed. Toronto: Churchill Livingstone; 2004:9-26.

14. Waddell G. Epilogue. In: The Back Pain Revolution. 2nd ed. Toronto: Churchill Livingstone; 2004:457-459.

15. Childs JD, Whitman JM, Sizer PS, Pugia ML, Flynn TW, Delitto A. A description of physical therapists' knowledge in managing musculoskeletal conditions. BMC Musculoskelet Disord. 2005;6:32.
16. Moore JH, Goss DL, Baxter RE, et al. Clinical diagnostic accuracy and magnetic resonance imaging of patients referred by physical therapists, orthopaedic surgeons, and nonorthopaedic providers. J Orthop Sports Phys Ther. 2005;35(2):67-71.

17. Boissonnault WG. Primary Care for the Physical Therapist: Examination and Triage. Toronto: Elsevier Ltd; 2005.

18. Hattam P. Evaluation of an orthopaedic screening service in primary care. Clin Perform Qual Health Care. 1999;7:121-124.

19. Daker-White G, Carr AJ, Harvey I, et al. A randomised controlled trial. Shifting boundaries of doctors and physiotherapists in orthopaedic outpatient departments. J Epidemiol Community Health. 1999;53: 643-650.

20. Jibuike OO, Paul-Taylor, G, Maulvl S, Richmond P, Fairclough J. Management of soft tissue knee injuries in an accident and emergency department: The effect of the introduction of a physiotherapy practitioner. Emerg Med J. 2003;20:37-39.

21. Hourigan PG, Weatherley CR. Initial assessment and follow-up by a physiotherapist of patients with back pain referred to a spinal clinic. J R Soc Med. 1994;87(4):213-214.

22. The Chartered Society of Physiotherapy. Making physiotherapy count. London, UK: The Chartered Society of Physiotherapy; 2004.

23. Aiken AB, McColl M. Interprofessional healthcare: A common taxonomy to assist with understanding. J Allied Health. 2009;38:e92-e96.

24. O'Cathain A, Froggett M, Taylor MP. General practice based physiotherapy: Its use and effect on referrals to hospital orthopaedics and rheumatology outpatient departments. Br J Gen Practice. 1995;45:352.

25. Hendriks EJ, Kerssens JJ, Dekker J, Nelson RM, Oostendorp RAB, van der Zee J. One-time physical therapist consultation in primary health care. Phys Ther. 2003;83:918.

26. Oldmeadow LB, Bedi HS, Burch HT, Smith JS, Leahy ES, Goldwasser M. Experienced physiotherapists as gatekeepers to hospital orthopaedic outpatient care. Med J Aust. 2007;186(12):625-628.

27. NHS Modernisation Agency, Department of Health. Improving orthopaedic services: A guide for clinicians, managers and service commissioners. London: NHS Modernisation Agency and Department of Health; 2002.

28. Alberta Bone and Joint Health Institute. Alberta hip and knee replacement pilot project. Alberta Bone and Joint Health Institute; 2007.

29. Aiken AB, Harrison MM, Atkinson M, Hope J. Easing the burden for joint replacement wait times: The role of the expanded practice physiotherapist. Healthc Q. 2008;11(2):62-66.

30. Weatherley CR, Hourigan PG. Triage of back pain by physiotherapists in orthopaedic clinics. $J$ R Soc Med. 1998;91(7):377-379.

31. Blackburn MS, Cowan SM, Cary B, Nall C. Physiotherapy-led triage clinic for low back pain. Aus Health Rev. 2009;33(4):663-670.

32. Jackson JL, Kroenke K. The effect of unmet expectations among adults presenting with physical symptoms. Ann Intern Med. 2001;134: 889-897.

33. Edwards I, Jones M, Higgs J, Trede F, Jensen G. What is collaborative reasoning? Adv Physiother. 2004;6:70-83.

34. Shadish WR, Cook TD, Campbell DT. Experimental and QuasiExperimental Designs for Generalized Causal Inference. New York: Houghton Mifflin Company; 2001.

35. Dillman DA, Smyth JD, Christian LM. Internet, Mail and Mixed-Mode Surveys: The Tailored Design Method. 3rd ed. Hoboken, New Jersey: John Wiley and Sons Inc; 2009.

36. Jensen MP, Turner JA, Romano JM. What is the maximum number of levels needed in pain intensity measurement? Pain. 1994;58:387-392.

37. Childs JD, Piva SR, Fritz JM. Responsiveness of the numeric pain rating scale in patients with low back pain. Spine. 2005;30(11):1331-1334.

38. Fairbank JC, Couper J, Davies JB, O’Brien JP. The Oswestry low back pain disability questionnaire. Physiother. 1980;66:271-273.

39. Fairbank JC, Pynsent PB. The Oswestry disability index. Spine. 2000;25:2940-2952.

40. Ware JE, Kosinski M, Bjorner JB, Turner-Bowker DM, Gandek B, Maruish ME. User's Manual for the SF-36v2 Health Survey. 2nd ed. Lincoln, RI: QualityMetric Incorporated; 2007. 
41. Main CJ, Wood PLR, Hollis S, Spanswick CC, Waddell G. The Distress And Risk Assessment Method. A simple patient classification to identify distress and evaluate the risk of poor outcome. Spine. 1992; 17:42-52.

42. Strauss A, Corbin J. Basics of Qualitative Research: Grounded Theory Procedures and Techniques. Newbury Park, CA: Sage Publications Inc; 1990.

43. Patton MQ. Qualitative Research and Evaluation Methods. 3rd ed. Thousand Oaks, CA: Sage Publications Inc; 2002.

44. American College of Sports Medicine. ACSM's Guidelines for Exercise Testing and Prescription. 5th ed. Baltimore, USA: Williams \& Wilkins; 1995.

45. Kennedy DM, Robarts S, Woodhouse L. Patients are satisfied with advanced practice physiotherapists in a role traditionally performed by orthopaedic surgeons. Physiother Can. 2010;62:298-305.

46. Royse D, Thyer BA, Padgett DK, Logan TK. Client satisfaction. In: Program Evaluation: An Introduction. 3rd ed. Toronto, Canada: Brooks/ Cole Thomson Learning; 1996:191-212.

47. Hudak PL, Wright JG. The characteristics of patient satisfaction measures. Spine. 2000;25(24):3167-3177.

48. Ware JE, Snyder MK, Wright WR, Davies AR. Defining and measuring patient satisfaction with medical care. Eval Prog Plan. 1983;6: 247-263.

49. Ferris LE and the Health Services Research Group. A guide to direct measures of patient satisfaction in clinical practice. Can Med Assoc J. 1992;146:1727-1731.

50. Pascoe GC. Patient satisfaction in primary health care: A literature review and analysis. Eval Prog Plan. 1983;6:185-210.

51. Hill J, Bird HA, Hopkins R, Lawton C, Wright V. Survey of satisfaction with care in a rheumatology out-patient clinic. Ann Rheum Dis. 1992;51: 195-197.

52. Baker R. Development of a questionnaire to assess patients' satisfaction with consultations in general practice. Br J Gen Pract. 1990;40: 487-490.

53. McClellan CM, Greenwood R, Benger JR. Effect of an extended scope physiotherapy service of patient satisfaction and the outcome of soft tissue injuries in an adult emergency department. Emerg Med J. $2006 ; 23: 384-387$
54. Slade SC, Keating JL. Measurement of patient experience and satisfaction of exercise programs for low back pain: A structured literature review. Pain Med. 2010;11:1489-1499.

55. Campbell M, Fitzpatrick R, Haines A, et al. Framework for design and evaluation of complex interventions to improve health. $B M J$. 2000;321:694-696.

56. von Korff M, Moore JC. Stepped care for back pain: Activating approaches for primary care. Ann Int Med. 2001;134:911-917.

57. Rubin DI. Epidemiology and risk factors for spine pain. Neurol Clin. 2007;25(2):353-371.

58. Waddell G. The biopsychosocial model. In: Waddell G, editor. The Backpain Revolution. 2nd ed. Toronto: Churchill Livingston; 2004:265-282.

59. Greenhalgh S, Selfe J. Red Flags: A Guide to Identifying Serious Pathology of the Spine. Toronto: Churchill Livingstone; 2006.

60. Verbeek J, Sengers M, Riemens L, Haafkens J. Patient expectations of treatment for back pain. A systematic review of qualitative and quantitative studies. Spine. 2004;29(20):2309-2318.

61. Linton SJ, McCracken LM, Vlaeyen JW. Reassurance: Help or hinder in the treatment of pain. Pain. 2008;134:5-8. Epub November 26, 2007.

62. Goubert L, Crombez G, Danneels L. The reluctance to generalize corrective experiences in chronic low back pain patients: A questionnaire study of dysfunctional cognitions. Behav Res Ther. 2005;43:1055-1067.

63. Jordan KP, Kadam KD, Haywards R, Porcheret M, Young C, Croft P. Annual consultation prevalence of regional musculoskeletal problems in primary care: An observational study. BMC Musculoskelet Disord. 2010;11(144):1471.

64. Lim KL, Jacobs P, Klarenbach S. A population-based analysis of healthcare utilization of persons with back disorders: Results from the Canadian Community Health Survey 2000-2001. Spine. 2006;31(2):212-218.

65. du Plessis V, Beshiri R, Bollman R, Clemenson H. Definitions of "rural." Agricultural and Rural Working Paper Series No 61. Ottawa: Statistics Canada Agriculture Division; 2002. 


\section{Appendix: Diagnostic and management classification questionnaire Diagnosis}

Based on the clinical findings (ie, history, symptom behavior/ location, physical exam findings, and imaging findings (if available)), please answer the following questions:

1. What are this client's presenting symptoms likely due to?

a. A problem in the back?
$\square$ Yes
$\square$ No

b. Is it likely a medical problem (eg, genitourinary, systemic)?

$\square$ Yes $\square$ No

c. Is it likely a mechanical/degenerative problem from elsewhere (eg, hip, knee)?

$\square$ Yes

$\square$ No

List:-

2. Is there likely a spinal cord or cauda equina lesion?

$\square$ Yes $\quad \square$ No

Back pain diagnostic triage

3. Indicate which category best fits the clinical presentation:

a. Possible serious spinal pathology

$\square$ Yes $\quad \square$ No

b. Nerve root problem

$\square$ Yes $\quad \square$ No

c. Non-specific back pain

$\square$ Yes $\quad \square$ No
4. Indicate what the likely source of the nerve root problem is:
a. none
$\square$ Yes
$\square$ No
b. discogenic
$\square$ Yes
$\square$ No
c. stenosis
$\square$ Yes
$\square$ No

Management recommendations

6. Indicate what your recommended treatment plan is (check all that apply)
a. No further follow-up
$\square$ Yes $\square$ No
b. Urgent surgical consult
$\square$ Yes $\square$ No
c. Emergency surgical consult $\square$ Yes $\square$ No
d. Referral to another specialist $\square$ Yes $\square$ No

List:

e. Physiotherapy/rehabilitation (with or without PT consultant review)

$$
\square \text { Yes } \square \text { No }
$$

f. PT treatment and surgical referral $\square$ Yes $\square$ No

g. Advanced imaging (ie, CT or MRI) $\square$ Yes $\square$ No

Abbreviations: PT, physiotherapist; CT, computed tomography; MRI, magnetic resonance imaging.
Journal of Multidisciplinary Healthcare

\section{Publish your work in this journal}

The Journal of Multidisciplinary Healthcare is an international, peerreviewed open-access journal that aims to represent and publish research in healthcare areas delivered by practitioners of different disciplines. This includes studies and reviews conducted by multidisciplinary teams as well as research which evaluates the results or conduct of such teams or

\section{Dovepress}

healthcare processes in general. The journal covers a wide range of areas and welcomes submission from practitioners at all levels, from all over the world. The manuscript management system is completely online and includes a very quick and fair peer-review system. Visit http://www.dovepress.com/testimonials.php to read real quotes from published authors. 